\title{
Characteristics of shisha smoking venues in a satellite township near Kuala Lumpur, Malaysia: an observational study.
}

\author{
Kalyan C Gundavarapu ${ }^{I}$, Daniel D Dicksit ${ }^{1}$, Srinivas Sulugodu Ramachandra ${ }^{1}$
}

\begin{abstract}
INTRODUCTION Shisha smoking has emerged as a popular trend in Malaysia, especially around the capital city of Kuala Lumpur. The aim of this study was to determine the environment and services provided in shisha venues around the satellite township of Petaling Jaya near Kuala Lumpur, Malaysia.

METHODS Trained observers visited 41 restaurants providing shisha smoking services in and around Petaling Jaya, near Kuala Lumpur, Malaysia in late 2014 / early 2015. Observations on the location, operating time, number of shisha instruments, rental price, seating capacity, ventilation facilities, display of license, and distance from educational institutions $(<1 \mathrm{~km}$ vs. $>1 \mathrm{~km}$ ) was recorded.

RESULTS Total seating capacity in shisha venues ranged from 20 to 132 with 6-68 shisha instruments. Shisha venues opened were open from 6:00 PM to 2:00 AM on weekdays. Rental charges ranged from USD 1.00/- to USD 7.00/- with an average of 2.8 USD. Shisha venues nearer to educational institutions had on average a higher number of units ( $60 \mathrm{vs.} 30, \mathrm{p}<0.001)$, however a smaller number of seats ( $30 \mathrm{vs.} 55, \mathrm{p}<0.001)$.

ConcLusions A large number of shisha venues are present in the satellite township near Kuala Lumpur. The shisha venues located within 1000 meters of educational institutions and universities had a higher density of units/seats.
\end{abstract}

\author{
AFFILIATION \\ 1 Faculty of Dentistry. \\ SEGi University \\ CORRESPONDENCE TO \\ Srinivas Sulugodu Ramachandra, \\ Faculty of Dentistry, SEGi \\ University, No. 9 Jalan \\ Teknologi, Taman Sains, 47810 \\ Petaling Jaya,, Malaysia. Email: \\ periosrinivas@gmail.com \\ KEYWORDS \\ Tobacco, Malaysia, Policy, \\ Shisha smoking, Centers
}

\section{INTRODUCTION}

A report by the World Health Organization in 2010 stressed the dangers of shisha smoking, with second hand smoke emanating from shisha smokers also unsafe for non-smokers.1 Shisha smoking is a popular trend in Malaysia especially among youth ${ }^{2}$. Presently the tobacco control laws in Malaysia do not address the sale and consumption of shisha products, so vendors which has lead to the opening up of many shisha venues around the city of Kuala Lumpur ${ }^{2}$. The aim of this study was to determine the environment and services provided, in shisha venues around the satellite township of Petaling Jaya near Kuala Lumpur, Malaysia. For the sake of uniformity in the article, we have used the term "shisha venues" for shisha bars, shisha lounges and shisha restaurants.

\section{METHODS}

\section{Study Design}

Shisha venues in and around the city of Petaling Jaya were located using google maps under the category "search nearby".
The terms used to conduct search on google maps were "shisha centers/ shisha lounges/ shisha bars" and "Petaling Jaya. This online search provided us with 41 shisha venues in and around Petaling Jaya. Since the study was observational, without involving human or animals, ethical approval was not obtained.

This study was conducted between December 2014 and February 2015 by two observers (KCG and SRS) who visited 41 shisha venues. Some of the venues served shisha exclusively, whereas others provided shisha smoking services in addition to serving food.

Training of the observers: Three researchers (KCG, SRS and DDD) prepared and agreed upon a checklist which was used to record the observations in each of the shisha venues. Observations on the location of the shisha venue, the operating time of the venue, the number of shisha instruments available, rental price, seating capacity, air ventilation facilities, display of the license for the shisha venue, availability of 


\section{Research Paper}

Table 1: Comparison of shisha venue characteristics within 1000 meters and beyond 1000 meters of educational institutions in Petaling Jaya, Malaysia.

\begin{tabular}{|c|c|c|c|}
\hline & $\begin{array}{l}1000 \text { meters } \\
\text { V(\%) }\end{array}$ & $\begin{array}{l}1000 \text { meters } \\
\mathrm{N}(\%)\end{array}$ & PValue \\
\hline Number of outlets & $23(56)$ & $18(44)$ & \\
\hline Average No of seats & 30.0 & 55.9 & $p=0.0001^{*}$ \\
\hline Average No of units & 60.2 & 30.2 & $p<0.0001^{*}$ \\
\hline Average Price in US dollar & 2.725 & 2.925 & $p=0.6882^{*}$ \\
\hline Ventilation systems available & $7(30.4)$ & $8(33.3)$ & $p=0.8889^{* *}$ \\
\hline Disposable tips not available & $6(21.6)$ & $4(22.2)$ & $p=0.7383^{* *}$ \\
\hline \multicolumn{4}{|l|}{ Ventilation } \\
\hline Open & $6(26.1)$ & $5(27.8)$ & $p=0.8161^{* *}$ \\
\hline Closed & $3(13.0)$ & $2(11.1)$ & $p=0.7648^{* *}$ \\
\hline Semi open & $8(34.8)$ & $5(27.8)$ & $p=0.8880^{* *}$ \\
\hline Both & $6(26.1)$ & $6(33.3)$ & $p=0.8763^{* *}$ \\
\hline
\end{tabular}

${ }^{*}$ T test (Two tailed probability) ** Chi-squared test

disposable mouthpieces for groups of users, and distance from educational institutions $(<1 \mathrm{~km}$ vs. $>1 \mathrm{~km})$ was recorded. Online advertising, and was also observed. Observers also searched for the webpage of these venues on social media sites.

Independent sample $\mathrm{t}$ test assuming equal variances was used on the data collected with a p value set at 0.05 . Simple descriptive statistics of the observed findings were analysed using MedCalc ${ }^{13}$.

\section{RESULTS}

Fifty six percent $(n=23 / 41)$ of venues operated within 1000 meters of educational institutions. Total seating capacity ranged from 20 to 132 (mean 58.3) with 6-68 (mean 15.2) shisha instruments. Table 1 shows the relation between seating capacity, shisha units and pricing at shisha venues in relation to the distance to an educational institution.

Most of the shisha venues usually started their services from 6:00 PM to 2:00 AM on weekdays. On weekends, most of the shops started their services from 2:00 PM itself. Venues which were offering shisha services in

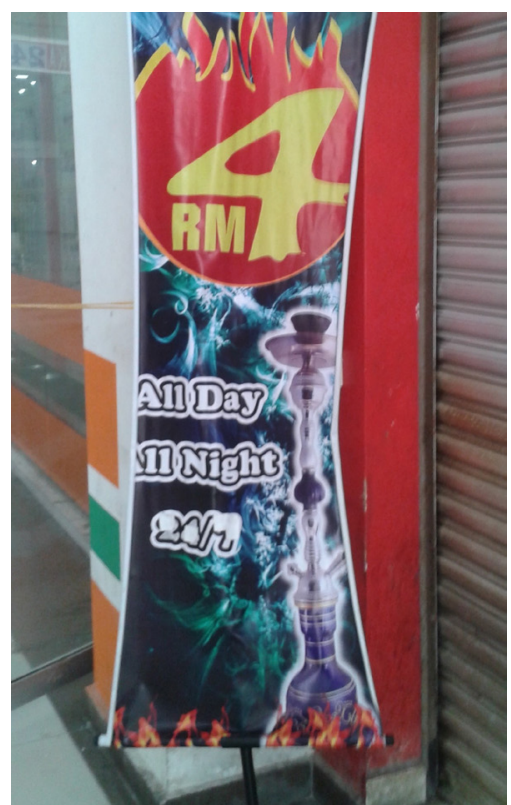

a closed environment accounted for $12.2 \%(n=5)$ of venues; open environment $26.8 \%(n=11)$; semi open/ high roof $31.7 \%$ $(n=13)$ and those offering in both closed and open are $29.3 \%$ (12). No special air ventilation system of exhaust fans or air conditioner/ air blowers were seen in $68.3 \%(n=28)$ while some kind of ventilation system was seen in $31.7 \%(n=13)$. Rental charges ranged from USD 1.00/- to USD 7.00/- with an average of USD 2.8/-. Some shisha venues which offered less expensive services did not provide disposable plastic tip $24.4 \%(n=10)$ for shared users. On site advertising by use of banners and posters are seen in $17.1 \%(n=7)$ while display of units in the front of the center itself in the evening time is used as advertising of the services. No official license

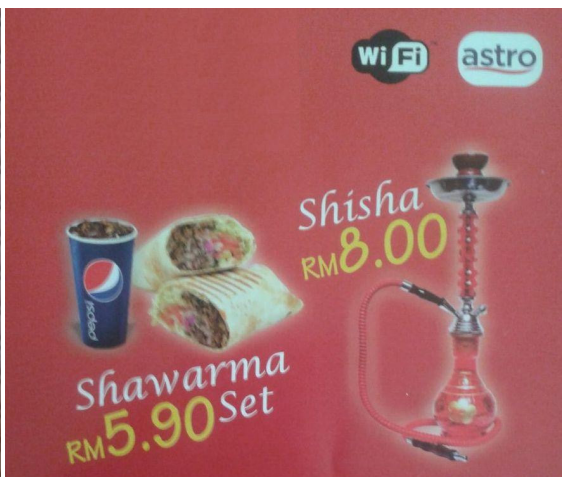

"60+t" Kinds of BestArab Food

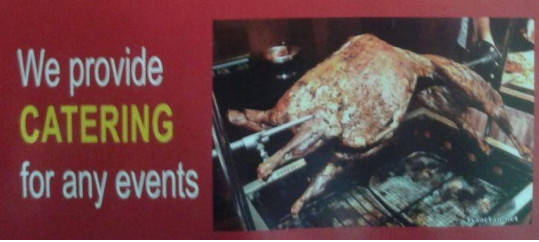
from the government to offer shisha services was observed in any of the venues.

Some shisha venues even provided catering services to birthday parties and wedding functions (Figures 1\&2). All the venues which were seen in the google maps results also had a dedicated page of their own on social media. 


\section{DISCUSSION}

Petaling Jaya is a major Malaysian city originally developed as a satellite township near Kuala Lumpur ${ }^{4}$. Petaling Jaya is home to many educational universities, business establishments, eateries and recreation venues ${ }^{4}$. There are many public and private universities around Petaling Jaya, near Kuala Lumpur. It is mandatory for these universities to recruit a certain percentage of international students to maintain their University status. The Ministry of Education which oversees all the private and public universities in Malaysia, also encourages enrollment of international students and aims to make Malaysia an international education hub by $2020^{6}$.

Majority of the international students studying in Malaysia are from Middle Eastern, Central Asian and Northern African countries ${ }^{6}$. Usage of shisha smoking is more of a tradition and in the culture among students from these regions. So, many international students studying in these universities practice shisha smoking. This explains the clustering of shisha venues around these institutions. Operating time of these venues also suits the timing of the students. Most of the places start by evening 6:00 PM and operate till 2:00 AM, which suits the free or leisure time of students. On weekends, shisha venues start by 2:00 PM, keeping in mind to cater to the free time of students.

Al-Naggar et al, studied the pattern, related knowledge and risk factors for shisha smoking among Malaysians ${ }^{7}$. They concluded that Malaysians had relatively low knowledge about shisha smoking and the prevalence of shisha smoking was high among Malaysians ${ }^{7}$. Al-Naggar et al, also studied the associated risk factors for shisha smoking among University students. Among 200 university students, 30\% were shisha smokers and their knowledge regarding dangers of shisha smoking was low. Income and gender significantly influenced the practice of shisha smoking among university studnets ${ }^{8}$.

Second-hand smoke emanating from shisha venues is also dangerous for non-smokers.1 Shisha unit density for the venues within the radius of 1000 meters from educational institutions was 0.5 , and 1.9 for venues more than 1000 meters from educational institutions. A low number of seats per unit indicate a higher density of shisha instruments and hence also potentially a higher exposure to second hand smoke from water pipes are seen in those venues which are within $1000 \mathrm{~m}$ of educational institutions.

Among the shisha venues studied, 56\% were within $1 \mathrm{~km}$ distance of educational institutions. The impact of proximity of these shisha venues to educational institutions could be dangerous. Agaku et al., investigated the impact of proximity of tobacco retail outlets to schools on tobacco-related behaviour and attitudes of school personnel in sub-Saharan Africa' ${ }^{9}$.There was a significant association between the presence of tobacco outlets on school premises and current cigarette smoking, current smokeless tobacco use and permissiveness towards tobacco industry sponsorship activities in school. Agaku et al., stressed the need for policies limiting tobacco outlets from school premises ${ }^{9}$. Jaber et al., studied whether shisha smoking could act as a gateway, leading to initiation of smoking among youth in Jordan ${ }^{10}$. The authors concluded that shisha smoking led to initiation of cigarette smoking in Jordanian adults and the effect was dose dependent ${ }^{10}$.

Advertising on social media has been used effectively by several businesses. Low cost and increased penetrability especially among youth may be the main reasons for vendors to choose social media as means to promote or advertise their businesses. Maziak et al. opined that one of the technological inventions that promoted shisha smoking across the world and especially among the youth was the internet ${ }^{11}$. Salloum et al. reported that web-based searches for shisha smoking had steadily increased since 2004 in Australia, Canada, the United Kingdom and the United States of America ${ }^{12}$. They also reported that online searches were primarily targeted for shisha products for home use, followed by searches for shisha venues. Krauss et al., analysed chatter content about shisha on twitter. Analysis showed that 19\% were advertisements/ promotions for shisha venues/ products ${ }^{13}$.

Shisha venues providing catering services to birthday parties and wedding functions should be considered as worrying trend. This not only indicates popularity of shisha among youth but also giving signs of social and cultural acceptability. Amin et al. reported that shisha smoking had more social acceptability than cigarettes and represented a good opportunity during a get together of family and friends ${ }^{14}$. Afifi et al. concluded from their study conducted in the Eastern Mediterranean region that increased socio-cultural acceptability was one of the main reasons for wide spread and instant popularity of shisha smoking ${ }^{15}$.

Rental prices for one shisha smoking session (per hour) varied from USD 1.0 to 7.0 /-. Smaller venues offered shisha usage in the lower price bracket, whereas bigger venues charged in the higher price bracket. Compared to traditional cigarette usage, shisha smoking is cheaper because of the amount of time shisha can be smoked and since shisha is usually shared among a group of friends ${ }^{16}$.

In none of the shisha venues there was any display of license to offer shisha services. An Islamic religious fatwa committee has banned the sale and smoking of shisha in Malaysia ${ }^{17}$, however, this ban is of no much relevance since it has does not 
have the legitimacy of the government. The states of Malacca and Kelantan state governments were the first to ban sale of shisha in 2011 but no clear policy on shisha smoking has been put in place $^{18}$. There have been calls from Malaysian Council for Tobacco Control to amend the Control of Tobacco Product Regulations $2004 \mathrm{act}^{19}$. The health ministry is contemplating on a possible temporary ban on shisha smoking in Malaysia to address these problems ${ }^{20}$.

Operations and services of shisha venues around the city of Kuala Lumpur may be similar to that of Petaling Jaya so, generalization of the results of this study from the township of Petaling Jaya to other parts of Kuala Lumpur, may be possible. Limitations of the study included the fact that the study field also had venues which were not noted in the Google search. This factor may have led to an underestimation of the number of shisha venues as several small venues which also offered shisha smoking and were not present online.

\section{CONCLUSION}

A significant number of shisha venues are present in the satellite township near Kuala Lumpur. The shisha venues were located more within 1000 meters of educational institutions and universities, and differences were noted with regards to their seating density and size. The Health Ministry could come out with a clear legal framework and policy to ban shisha venues and also encourage those in this business to shift to other business.

\section{REFERENCES}

1. WHO study group on tobacco product regulation (TobReg). Waterpipe tobacco smoking: health effects research needs and recommended actions by regulators.[Internet] Geneva, (Switzerland) World Health Organization; 2005 Available from: http://www. who.int/tobacco/global_interaction/tobreg/Waterpipe $\% 20$ recommendation_Final.pdf. (accessed Jan 2016)

2. Ramachandra SS, Yaldrum A. Shisha smoking: An emerging trend in Southeast Asian nations. J Public Health Policy. 2015; 36(3):304317. doi: 10.1057/jphp.2015.16

3. von Elm E, Altman DG, Egger M, Pocock SJ, Gotzsche PC, Vandenbroucke JP; STROBE Initiative. The Strengthening the Reporting of Observational Studies in Epidemiology (STROBE) Statement: guidelines for reporting observational studies. Int J Surg. 2014;12(12):1495-1499. doi: 10.1016/j.jijsu.2014.07.013

4. Wikipedia. Petaling Jaya[Internet]. Malaysia:Wikipedia; 2015 Available from https://en.wikipedia.org/wiki/Petaling_Jaya (accessed April 2016)

5. Ain Arabia Kuala Lumpur[Internet].Malaysia:Malaysiavacationguide. com; 2015 Available from http://www.malaysiavacationguide.com/ ain-arabia.html. (accessed April 2016)

6. Datuk Seri Idris Jusoh Malaysia as education hub looks positive. Malaysia: The Star Online: (2014). Available from http://www. thestar.com.my/News/Nation/2014/06/21/Msia-as-educationhub-looks-positive/.(accessed April 2016)
7. Al-Naggar RA, Bobryshev YV, Anil S. Pattern of shisha and cigarette smoking in the general population in Malaysia. Asian Pac J Cancer Prev. 2014;15(24):10841-6.

8. Al-Naggar RA, Saghir FS. Water pipe (shisha) smoking and associated factors among Malaysian university students. Asian Pac J Cancer Prev. 2011;12(11):3041-7.

9. Agaku IT, Adisa AO, Omaduvie UT, Vardavas CI. The relationship between proximity of tobacco retail outlets to schools and tobacco use among school personnel in sub-Saharan Africa. Prev Med. 2014 Dec;69:21-7. doi: 10.1016/j.ypmed.2014.08.018

10. Jaber R, Madhivanan P, Veledar E, Khader Y, Mzayek F, Maziak W. Waterpipe a gateway to cigarette smoking initiation among adolescents in Irbid, Jordan: a longitudinal study. Int J Tuberc Lung Dis. 2015 Apr;19(4):481-7. doi: 10.5588/ijtld.14.0869.

11. Maziak W, Taleb ZB, Bahelah R, Islam F, Jaber R, Auf R, et al. The global epidemiology of waterpipe smoking. Tob Control. 2015;24(1):i3-i12. doi: 10.1136/tobaccocontrol-2014-051903

12. Krauss MJ, Sowles SJ, Moreno M, Zewdie K, Grucza RA, Bierut LJ, et al. Hookah-Related Twitter Chatter: A Content Analysis. Prev Chronic Dis. 2015;12:E121. doi: 10.5888/pcd12.150140.

13. Salloum RG, Osman A, Maziak W, Thrasher JF. How popular is waterpipe tobacco smoking? Findings from internet search queries. Tob Control. 2014 24(5): 509-513. doi: 10.1136/ tobaccocontrol-2014-051675

14. Amin TT, Amr MA, Zaza BO, Suleman W. Harm perception, attitudes and predictors of waterpipe (shisha) smoking among secondary school adolescents in Al-Hassa, Saudi Arabia. Asian Pac J Cancer Prev. 2010;11(2):293-301.

15. Afifi R, Khalil J, Fouad F, Hammal F, Jarallah Y, Abu Farhat H, et al. Social norms and attitudes linked to waterpipe use in the Eastern Mediterranean Region. Soc Sci Med. 2013;98:125-134. doi: 10.1016/j.socscimed.2013.09.007.

16. Blank MD, Brown KW, Goodman RJ, Eissenberg T. An observational study of group waterpipe use in a natural environment. Nicotine Tob Res. 2014;16(1):93-99. doi: 10.1093/ntr/ntt120.

17. Bernama. National fatwa committee bans shisha smoking[Internet]. Malaysia: Malaysian Insider; 2013. Available from http://www. themalaysianinsider.com/malaysia/article/national-fatwacommittee-bans-shisha-smoking. (accessed April 2016)

18. Kelantan Banning Shihsa too.[Internet].Malaysia:Malaysia today;2013 Available from http://www.malaysia-today.net/kelantanbanning-shisha-too/. (accessed April 2016)

19. Bernama. Amend Tobacco Laws.[Internet].Malaysia:Free Malaysia Today; Available from http://www.freemalaysiatoday.com/ category/nation/2013/07/22/\%E2\%80\%98amend-tobaccolaws $\% \mathrm{E} 2 \% 80 \% 99 /$. (accessed April 2016)

20. Bernama. Temporarily stop e-cigarettes and shisha smoking, says Dr Subramaniam. Malaysia: Astrowani; 2015 Available from http://english.astroawani.com/ malaysia-news/temporarily-stope-cigarettes-and-shisha-smokingsays-dr-subramaniam-69548 (accessed April 2016)

CONFLICT OF INTEREST All the authors have completed and submitted the ICMJE Form for Disclosure of Potential Conflicts of Interest and none were reported.

FUNDING

There was no source of funding for this research.

PROVENANCE AND PEER REVIEW

Not commissioned; Externally peer reviewed 